\title{
O DIREITO AO ESQUECIMENTO ANTE O CONFLITO DE DIREITOS FUNDAMENTAIS NAS PROPAGANDAS ELEITORAIS NA INTERNET
}

\section{Marcela Queiroz de França Damázio}

Mestranda em Direitos Humanos pela Universidade Tiradentes, Aracaju-SE, Campus Farolândia. E-mail: mamaqueiroz@gmail.com.

\section{Diogo de Calasans Melo Andrade}

Doutor em Direito pela Mackenzie. Mestre em Direito pela UFS. Pesquisador e Professor do Mestrado e Doutorado em Direitos Humanos da Universidade Tiradentes, Aracaju-SE, Campus Farolândia PPGD-UNIT. E-mail: contato@diogocalasans.com.

\begin{abstract}
Resumo: Atualmente, chega a ser repetitivo o chamamento à reflexão de que o mundo digital nos possui. Estamos imersos, como um todo, nesta rede de dados, contatos, informações e interações. Nesta perspectiva, o presente estudo busca fazer uma análise crítica sobre como alguns direitos fundamentais entram em conflito no ambiente virtual, na perspectiva da campanha eleitoral. Considerase, principalmente, como o direito à honra, à privacidade e à imagem são constantemente contrapostos ao da liberdade de expressão e de informação, principalmente com as facilidades permitidas pelo ambiente virtual. A hipótese levantada é a de que, assim como todo direito fundamental, a liberdade de expressão não é absoluta, devendo observância a direitos que resguardam a personalidade, citando o direito ao esquecimento um balizador na ponderação entre tais direitos. 0 método a ser usado para a referida pesquisa será, primordialmente, o método dedutivo, buscando, a partir da ideia geral da problemática posta (conflito de direitos fundamentais), explorar suas especificidades, investigando especialmente as possiveis alternativas.
\end{abstract}

Palavras-chave: Direito ao esquecimento. Democracia. Direitos da personalidade. Liberdade de expressão. Campanha eleitoral.

Sumário: Introdução - 1 Campanhas eleitorais na era digital: novos contornos da democracia representativa - $\mathbf{2}$ Conflito entre direitos da personalidade e liberdade de expressão na campanha eleitoral na internet - $\mathbf{3} 0$ direito ao esquecimento como instrumento de preservação de direitos fundamentais - Considerações finais - Referências 


\section{Introdução}

A internet vem reconfigurando uma série de vertentes da vida humana: as formas de interação social, cultural, política e econômica. A cada dia, a rede globalizada confere novos contornos às atividades sociais, em que se incluem as campanhas eleitorais.

O sistema representativo adotado pela democracia brasileira não se quedou inerte às mudanças do mundo digital, ganhando também novos delineamentos, principalmente na execução, pelos candidatos e partidos, da propaganda eleitoral.

As facilidades ocasionadas pela rede de acesso à internet, com sua interação e alcance globais, acesso barato e fácil, além da grande capacidade de armazenamento e acesso constante de dados, construiu um terreno atrativo para que os integrantes do pleito eleitoral explorassem seus apelos comunicativos com os cidadãos, destinatários da propaganda.

Neste sentido, observa-se a crescente utilização dos recursos e canais disponibilizados pelo ambiente virtual para o exercício da propaganda eleitoral, o que, a priori, não acarreta maiores implicações jurídicas. Porém, analisando tais relações de forma mais aprofundada, chega-se ao cerne da problemática proposta neste estudo: a exploração de informações dos candidatos pelos adversários no fito de desenvolver uma campanha eleitoral negativa, que não raras vezes fere direitos fundamentais como aqueles relacionados à personalidade.

Apesar de garantida a liberdade de expressão, opinião, manifestação do pensamento, informação e imprensa, há que se considerar que estes direitos não são absolutos, devendo, mesmo quando exercidos no ambiente virtual, considerar as balizas advindas de outros direitos fundamentais.

Logo, pretende-se, com a pesquisa que ora se inicia, fazer uma reflexão sobre o conflito entre direitos fundamentais nas campanhas eleitorais desenvolvidas na internet, citando exemplos do pleito de 2018 no Brasil, e apontando o direito ao esquecimento como um possível balizador de tal conflito.

De início, a pesquisa contextualizará as campanhas eleitorais na era digital, com a evolução dos meios de comunicação e o exercício da exposição de propostas e projetos eleitorais. O tópico seguinte apresentará a problemática referente ao conflito entre direitos da personalidade e liberdade de expressão na campanha eleitoral, para em seguida citar o papel do direito ao esquecimento como uma forma de resguardar a proteção da imagem, honra, vida privada etc.

O método a ser usado para a referida pesquisa será, primordialmente, o método dedutivo, buscando, a partir da ideia geral da problemática posta (conflito de direitos fundamentais), explorar suas especificidades, investigando especialmente as possiveis alternativas. 


\section{Campanhas eleitorais na era digital: novos contornos da democracia representativa}

O Brasil, em seu processo de retomada da democracia a partir de 1988, erigiu como fundamento de sua República tanto a dignidade da pessoa humana quanto a cidadania, valores que deveriam materializar e perpetuar a higidez do novo Estado Democrático de Direito.

Buscando superar as marcas do regime totalitário, os citados fundamentos transmutavam-se em valores cuja realização se fazia urgente e essencial. Além deles, a liberdade em suas múltiplas vertentes é homenageada enquanto direito fundamental, também se firmando como valor de destaque ímpar ao processo democrático.

Neste aspecto, pode-se incluir a cidadania, a dignidade e a liberdade no centro do ideal de democracia que se pretendia alcançar no Brasil que ressurge a partir do novo ordenamento constitucional, como verdadeiras pedras de toque deste.

O parágrafo único do artigo inaugural da Carta Magna brasileira estatui que todo poder emana do povo, que deve exercê-lo através de representantes eleitos ou diretamente. A democracia brasileira é exercida, em sua maioria, através da escolha de representantes do povo, reais detentores do poder, ou seja, traduzse na democracia indireta, em que os cidadãos exercem o direito subjetivo do sufrágio através do voto. ${ }^{1}$

Para garantir que a vontade popular chegue de forma hígida ao poder, é imprescindível a instauração de um processo eleitoral capaz de preservar a igualdade dos concorrentes, a lisura das eleições, a isonomia de oportunidades, a moralidade, tudo buscando preservar o caminho pelo qual deverá ser exercida a soberania popular. ${ }^{2}$

Dentro de tal sistemática, importante destacar o papel da propaganda eleitoral, aqui considerada o ato que busca expor à opinião pública tanto as propostas quanto os programas dos candidatos, visando angariar votos para que se sagrem eleitos. ${ }^{3}$ É através da campanha eleitoral que aqueles que pretendem representar o povo são capazes de expor seus projetos e ideologias basilares para os cidadãos, que decidirão o pleito e selecionarão seus representantes.

A construção da propaganda eleitoral perpassa a seleção de técnicas escoIhidas para convencer o eleitor a votar em determinado candidato, através de

MORAES, Alexandre de. Direito constitucional. 32. ed. São Paulo: Atlas, 2016. p. 58.

ALMEIDA, Roberto Moreira de. Curso de direito eleitoral. 12. ed. Salvador: JusPodivm, 2018. p. 61.

ALMEIDA, Roberto Moreira de. Curso de direito eleitoral. 12. ed. Salvador: JusPodivm, 2018. p. 408. 
uma argumentação que, na maior parte das vezes, busca desencadear estados emocionais para induzir o subconsciente de quem está recebendo a mensagem.

O órgão de cúpula da Justiça Eleitoral, o Tribunal Superior Eleitoral, traz a seguinte definição:

Ato de propaganda eleitoral é aquele que leva ao conhecimento geral, ainda que de forma dissimulada, a candidatura, mesmo que apenas postulada, a ação que se pretende desenvolver ou razões que induzam a concluir que o beneficiário é o mais apto ao exercício da função pública. ${ }^{4}$

A propaganda eleitoral é permitida a partir do dia 16 de agosto do ano eleitoral, vinculada a uma eleição específica, sendo uma prática essencial à democracia. A propaganda é a forma de comunicação entre aqueles que pretendem o poder (candidatos) e os que de fato o detém (povo).

Para resguardar direitos envolvidos, a propaganda deve observar alguns princípios, como o da legalidade, liberdade e responsabilidade. 0 princípio da legalidade prevê que as disposições legais, principalmente contidas na Lei de Eleições (Lei no 9.504/97), devem ser observadas quando no exercício da propaganda. ${ }^{5}$

Já o princípio da liberdade resguarda ser livre toda e qualquer manifestação de pensamento nas propagandas eleitorais, sem censura, controle prévio ou perturbação dos meios lícitos de fazê-la. O princípio da responsabilidade, por sua vez, surge como um contrapeso deste último. A ideia é que, se de um lado a expressão é livre, de outro há a possibilidade de responsabilização civil, penal e administrativa pelas ilicitudes, excessos e abusos cometidos, ${ }^{6}$ ou seja, o atingimento do direito de outrem.

Assim, percebe-se que o ordenamento jurídico busca resguardar a liberdade de expressão e manifestação nas prévias do pleito, enquanto resguarda eventuais responsabilidades que possam advir caso tal direito seja exercido de forma abusiva.

É importante pontuar também que, ao longo dos anos, as formas de comunicação vêm sofrendo grandes modificações. A internet proporcionou uma série de alterações consideradas paradigmáticas, trazendo novas experiências

4 Ac. $\mathrm{n}$ ㅇ 15.732/MA. Rel. Min. Eduardo Alckmin. DJ, 7 maio 1999. No mesmo sentido: Ac.-TSE n 16.183, de 17.2.2000. Rel. Min. Eduardo Alckmin; Ac.-TSE, de 27.2.2007, no ARESP no 26.196. Rel. Min. Geraldo Grossi; e Ac.-TSE no 16.426, de 28.11.2000, Rel. Min. Fernando Neves.

5 ALMEIDA, Roberto Moreira de. Curso de direito eleitoral. 12. ed. Salvador: JusPodivm, 2018. p. 409.

6 ALMEIDA, Roberto Moreira de. Curso de direito eleitoral. 12. ed. Salvador: JusPodivm, 2018. p. 410. 
interativas e participativas, não mais limitadas à capacidade humana e física, mas artificial e virtual, quase infinitas.

As relações sociais passaram a ser não apenas intermediadas pelas novas aplicações digitais, mas incentivadas e possibilitadas por elas. Segundo as ideias do filósofo francês Pierre Lévy, a própria linguagem das técnicas utilizadas para disseminá-la é fator que contribui para produzir e modular o espaço temporal ${ }^{7}$.

A internet foi e vem sendo capaz de alterar significativamente as interações sociais, culturais, políticas, ativistas, governamentais etc. Com acesso cada vez mais universal e democrático, permitindo que compartilhem do mesmo espaço de interação pessoas de diversos setores sociais, o fenômeno da globalização digital nos insere numa rede paritária de comunicação.

Para entender o sentido de tal rede ser paritária, sugere-se a reflexão sobre o painel informativo de décadas atrás. As fontes de informações disponíveis à população eram as concessionárias de rádio e TV e os jornais ou periódicos. Não raras vezes, tais veículos eram monopolizados por famílias ou grupos com interesses econômicos e políticos específicos e delimitados. Neste cenário, não é difícil perceber que a entrega da informação poderia apresentar cunho seletivo: noticiava-se o que tais grupos pretendiam para compor o ideário popular.

Por tais motivos se diz que a internet quebrou paradigmas. Ela permitiu a construção de um verdadeiro universo em que a informação pode ser veiculada por qualquer pessoa que a ela tenha acesso, ${ }^{8}$ ainda que não integrante de grupos específicos, o que permite não só uma democratização do acesso à informação como da disposição desta.

Neste aspecto, não se pode duvidar que a utilização do ambiente virtual, notadamente das redes sociais, tem sido uma crescente capaz de redefinir os parâmetros sociais de comunicação. Com a campanha eleitoral não seria diferente.

A prática informatizada da comunicação por candidatos a cargos eletivos, eleitores, parlamentares, gestores e sociedade civil pelos países do globo tem constituído o cenário chamado por Marques de ciberpolítica. ${ }^{9}$ Nele, as novas mídias surgem como plano de fundo de uma ordem comunicativa e informacional em torno da política, permitindo um estreitamento entre os emissores e receptores das disposições lançadas na internet.

O caráter relacional das redes sociais permite não só a troca de informações, mas a interação através de curtidas, comentários, compartilhamentos, direcionamentos, o que acarreta uma nova experiência política, principalmente durante o

\footnotetext{
LÉVY, Pierre. As tecnologias da inteligência. Rio de Janeiro: Editora 34, 1993. p. 76.

8 CASTELLS, Manuel. A galáxia da internet: reflexões sobre internet, negócios e sociedade. Lisboa: Fundação Calouste Gulbenkian, 2004. p. 201.

9 MARQUES, Francisco Paulo Jamil. Ciberpolítica: conceitos e experiências. Salvador: EDUFBA, 2016.
} 
período legalmente estabelecido para realização da campanha eleitoral (iniciada a partir do dia 16 de agosto do ano eleitoral). ${ }^{10}$

Neste sentido, a internet se tornou um ambiente atrativo para que candidatos e partidos disseminassem suas propostas. Além do baixo custo para acesso e publicações, se mostra um dos veículos com maior alcance de receptores, permitindo a chegada das publicações a um sem-número de pessoas das mais diversas classes, idades ou gêneros, em qualquer lugar do mundo.

Essa perspectiva gerou ainda o que Carlos Eduardo Manhanelli já citava, na década de 90, como marketing eleitoral, que tem tomado o mundo digital, em suas palavras:

O objetivo do marketing eleitoral consiste em implantar técnicas de marketing político e comunicação social integrados, de forma a angariar a aprovação e simpatia da sociedade, construindo uma imagem do candidato que seja sólida e consiga transmitir confiabilidade e segurança à população elevando o seu conceito em nível de opinião pública. ${ }^{11}$

O marketing aqui trazido pode ser concebido, ainda, como o empenho desprendido, normalmente utilizando-se técnicas de mercado, para conquistar o eleitor. ${ }^{12}$ Nota-se que, de fato, as facilidades do mundo virtual transmutaram a campanha num verdadeiro mercado de eleitores, em que os candidatos se utilizam de meios e linguagens de persuasão e indução previamente estudados.

\section{Conflito entre direitos da personalidade e liberdade de expressão na campanha eleitoral na internet}

A nova forma de comunicação reflete, também, uma nova forma de linguagem direcionada às campanhas eleitorais. Temos observado, inclusive no pleito eleitoral de 2018, como os políticos utilizaram-se de vocabulário menos rebuscado, no fito de aproximar os eleitores das suas causas.

Outro fenômeno proporcionado pela internet, também observado no pleito eleitoral de 2018, diz respeito ao convite feito por grande parte dos candidatos,

10 Art. 36 da Lei no 9.504/97.

11 MANHANELLI, Carlos Augusto. Eleição é guerra. São Paulo: Summus, 1992. p. 22.

12 REGO, Francisco Gaudêncio Torquato do. Marketing político e governamental: um roteiro para campanhas políticas e estratégias de comunicação. São Paulo: Summus, 1985. 
durante o horário eleitoral gratuito, para que as pessoas acessassem suas redes sociais e conhecessem a integralidade de suas propostas, notadamente pelo curto tempo disponível no horário eleitoral gratuito, ou pouca verba para produção de material gráfico.

Logo, nota-se como o ambiente virtual serviu como uma verdadeira extensão da propaganda no rádio e na televisão, através das concessões do Poder Público. Tem-se aí um fator social relevante, principalmente considerando que a maior parte dos candidatos dispõe de um tempo ínfimo para se manifestar no horário eleitoral gratuito, estabelecido pela Lei de Eleições (Lei no 9.504/97).

Além disso, é perceptível que a utilização da internet por candidatos e partidos não se limita à interação entre estes e os cidadãos. O ambiente virtual pode servir também, nestes casos, como verdadeiro arquivo de informações e dados sobre a vida pregressa dos candidatos adversários, sendo utilizado, muitas vezes, como instrumento para uma campanha eleitoral negativa.

Chega-se, assim, ao cerne da pesquisa ora proposta. 0 fato de a internet ter facilitado as relações sociais e servido como importante meio de propagação de discussões e propostas políticas sem dúvidas retrata uma importante contribuição à própria democracia brasileira.

Porém, é importante definir que a corrida pela vitória nas eleições envolve direitos fundamentais do ordenamento jurídico brasileiro, como a imagem, a honra, a vida privada, a privacidade etc. Os direitos humanos fundamentais em uma sociedade são verdadeiros parâmetros do grau de democracia em determinada sociedade. ${ }^{13}$

Para fins de diferenciação, insta pontuar que, ao passo em que os direitos humanos representam uma expressividade de tutela da dignidade humana em nível internacional, os direitos fundamentais seriam a incorporação, em determinado ordenamento jurídico, destes direitos humanos, positivados em um contexto constitucional. ${ }^{14}$

Entretanto, não é forçoso lembrar que a natureza dos direitos da personalidade busca resguardar a própria dignidade da pessoa humana, esculpida no art. 1ํㅡㄴ inc. III da Constituição Federal. ${ }^{15}$ Logo, é preciso que também no ambiente virtual sejam respeitados direitos como imagem, honra, vida privada, privacidade etc.

13 BRANCO, Paulo Gustavo Gonet. Aspectos da teoria geral dos direitos fundamentais. In: BRANCO, Paulo Gustavo Gonet; MENDES, Gilmar Ferreira; COELHO, Inocêncio Mártires. Hermenêutica constitucional e os direitos fundamentais. Brasília: Brasília Jurídica, 2000. p. 104.

14 ARAÚJO, Luiz Alberto David; NUNES JÚNIOR, Vidal Serrano. Curso de direito constitucional. São Paulo: Saraiva, 2009. p. 110.

15 BITTENCOURT, Illa Barbosa; VEIGA, Ricardo Macellaro. Direito ao esquecimento. Revista Direito Mackenzie, v. 8 , n. 2 , p. $45-58$. p. 47. 
Seria no mínimo incoerente permitir que, no cenário de disputa eleitoral, em que estão relacionados os valores mais caros ao exercício da cidadania do povo que constitui uma nação, houvesse o prejuízo a direitos fundamentais, como o da personalidade. Mas não é isso que a sociedade tem acompanhado nos últimos pleitos.

De início, como exemplo, citemos as notícias falsas disseminadas pela internet, que trazem graves afrontas aos direitos da personalidade. Estudos feitos pelo Grupo de Pesquisa em Políticas Públicas para o Acesso à Informação (GPOPAI), da Universidade de São Paulo (USP), apontam que, em média, 12 milhões de pessoas compartilharam as chamadas fake news no Brasil em junho de 2018 (frise-se, ano eleitoral).

Tal pesquisa acompanhou 500 páginas digitais que apresentavam conteúdo político distorcido ou falso, com potencial de alcançar a maior parte dos eleitores brasileiros, considerando todas as facilidades permitidas pelo mundo digital já reforçada em linhas anteriores. ${ }^{16}$

O fenômeno das fake news foi experimentado numa intensidade jamais vista em campanha eleitoral. Mas também pudemos presenciar o reavivar de fatos passados que, embora verdadeiros, foram usados e manipulados para construir uma imagem negativa de outro candidato.

Pretende-se trazer à reflexão a possibilidade da divulgação e utilização de dados verdadeiros, mas bastante antigos, no ambiente das eleições, para construir uma imagem negativa da parte contrária. Isso porque, considerando o próprio grau de evolução humana, nem sempre somos e pensamos aquilo que um dia foi veiculado na mídia.

Uma série de exemplos pode ser destacada do pleito eleitoral ocorrido no Brasil em 2018. Cita-se, por ora, aquele relacionado ao candidato à presidência da República, Jair Bolsonaro, que teve diversos vídeos seus, antigos, com conteúdo que remetiam sua defesa à tortura, ditadura e intolerância, utilizados para reafirmar tais predicados em relação ao candidato, que se sagrou eleito. Muito embora verdadeiras as alegações ali veiculadas, o contexto histórico representava um período bastante longínquo.

Os direitos da personalidade dos candidatos são constantemente atingidos pelas campanhas eleitorais de seus adversários, ainda que com a divulgação de notícias verdadeiras. Se há 10 anos um deles manifestou apoio à ditadura, afirmando que esta deveria ter matado mais pessoas, tal recorte será repassado exaustivamente na campanha adversária para construir uma imagem de torturador.

16 MONNERAT, Alessandra; RIGA, Matheus; RAMOS, Pedro. Fake news devem causar impacto em eleições de 2018. Estadão. Disponível em: http://infograficos.estadao.com.br/focas/politico-em-construcao/ materia/fake-news-devem-causar-impacto-em-eleicoes-de-2018. Acesso em: 11 dez. 2018. 
Se há outros tantos anos determinado candidato participou de um evento e trocou alguns minutos de conversa com líderes de interesses controversos, a fotografia será vinculada indiscriminadamente, com legendas apontando os mais diversos contextos negativos.

Tais divulgações são capazes de interferir de forma tal no convencimento eleitorado, que acabam por construir personas diversas a depender de fatores como o nível de instrução dos receptores da notícia ou seu posicionamento político-social.

Logo, o que pode acontecer, e de fato aconteceu em 2018, é a formação de uma grande comoção social, positiva ou (mas principalmente) negativa, capaz de moldar o cenário da disputa eleitoral em uma arena das mais variadas ofensas a direitos da personalidade.

Entretanto, não raras as vezes, a proteção a tais direitos entra em conflito com outro direito fundamental, considerado valor indissociável do Estado Democrático de Direito: a liberdade de expressão. Esta, protegida constitucionalmente no art. 220 da Carta Magna brasileira, ainda tem sido privilegiada em detrimento dos direitos da personalidade, garantindo que a sociedade obtenha informações sobre os candidatos, seus programas, projetos e seu passado.

Os direitos da personalidade podem ser particularmente vulneráveis na era digital, basicamente diante do impacto cada vez mais sofisticado das tecnologias de informação. Neste sentido o direito precisa oferecer respostas necessárias e minimamente eficazes para este contexto. ${ }^{17}$

\section{0 direito ao esquecimento como instrumento de preservação de direitos fundamentais}

Considerando os argumentos apresentados anteriormente, nota-se que há um conflito de direitos fundamentais, com contornos bastantes específicos, quando se analisa o desenrolar da campanha eleitoral no ambiente virtual. É que o uso massivo da internet, com a crescente busca pela exposição da própria vida privada e o interesse pela alheia, notadamente através do uso de redes sociais, demandou um aumento nos sistemas de armazenamento de dados. ${ }^{18}$

SARLET, Ingo Wolfgang. Proteção da personalidade no ambiente digital: uma análise à luz do caso do assim chamado direito ao esquecimento no Brasil. Espaço Jurídico Journal of Law, Joaçaba, v. 19, n. 2, p. 491-530, maio/ago. 2018. Disponível em: https://portalperiodicos.unoesc.edu.br/espacojuridico/ article/view/17557/pdf. Acesso em: 13 abr. 2020. p. 491.

18 LIMA, Erik Noleta Kirk Palma. Direito ao esquecimento: discussão europeia e sua repercussão no Brasil. Revista de Informação Legislativa, ano 50, n. 199, jul./set. 2013. p. 272. 
Temos, com isso, que o ambiente virtual se tornou um verdadeiro e gigantesco arquivo destes, rompendo as fronteiras físicas e espaciais da realidade material. São inúmeros conteúdos que podem ser armazenados, como entrevistas e reportagens, fotos, vídeos, publicações, artigos etc. Tudo guardado indefinidamente no tempo. Além disso, os dados são não apenas facilmente armazenados como revisitados a qualquer tempo.

Neste sentido, há uma grande facilidade em se conseguir imagens ou publicações que dizem respeito a uma pessoa, e utilizá-las em determinada campanha. A grande questão, como já foi dito, é o uso da imagem de outrem em campanha eleitoral, de forma indiscriminada, no fito de lhe imputar aspectos negativos, ferindo não só sua honra como sua imagem.

Apesar dos dispositivos constitucionais e infraconstitucionais que protegem tanto os direitos da personalidade quanto a liberdade de expressão, a velocidade com que os fatos sociais se desenvolvem no mundo virtual está demandando respostas cada vez mais específicas dos operadores do direito.

Aqui, aponta-se tanto a necessidade de uma normatização acerca do uso de dados e informações pretéritas no âmbito da campanha eleitoral na internet, quanto o papel do Poder Judiciário que, a partir de cada caso concreto, é capaz de traçar os delineamentos adequados para a salvaguarda de determinado direito fundamental.

Quanto à utilização da internet, uma das normas mais importantes no país é a Lei do Marco Civil da Internet (Lei no 12.965/2014), que estabeleceu princípios, garantias, direitos e deveres para o uso da internet no Brasil.

Tal diploma legal, mesmo não prevendo expressamente o direito ao esquecimento, contém importantes diretrizes e regras concretas que podem ser reconstruídas para fins de se reconhecer a necessidade de acolhimento dessa pretensão jurídica individual em determinados casos, conforme se vê dos seguintes dispositivos que, interpretados sistematicamente, reconduzem à conclusão que aponta para a existência do direito ao esquecimento no direito nacional, além de regular aspectos específicos relativos a tal direito fundamental, dando-lhe concretude ao menos parcial. ${ }^{19}$

19 SARLET, Ingo Wolfgang. Proteção da personalidade no ambiente digital: uma análise à luz do caso do assim chamado direito ao esquecimento no Brasil. Espaço Jurídico Journal of Law, Joaçaba, v. 19, n. 2, p. 491-530, maio/ago. 2018. Disponível em: https://portalperiodicos.unoesc.edu.br/espacojuridico/ article/view/17557/pdf. Acesso em: 13 abr. 2020. p. 500. 
Nota-se que a preocupação do legislador, na edição de tal norma, seria garantir ao usuário da internet os direitos já inseridos na Constituição, com a peculiaridade do ambiente em que se enquadra. As disposições sobre privacidade, por exemplo, proíbem empresas de internet de repassarem os dados de seus clientes a terceiros, evitando abordagens publicitárias indesejáveis.

Por outro lado, também cria diretrizes para que determinados conteúdos sejam retirados do ar, vez que não havia qualquer regramento específico sobre o tema. Agora, a retirada do conteúdo da rede pode ser feita, desde que, e somente se, haja ordem judicial neste sentido. Entregar esta tarefa ao Judiciário tem como ponto positivo contar sua imparcialidade, não deixando a decisão nas mãos dos provedores da internet, que podem ser influenciados por questões políticas, econômicas etc.

Em relação ao papel do Poder Judiciário na construção de garantias relativas ao direito ao esquecimento, interessante análise é feita por Viana em relação ao comportamento da Justiça Eleitoral, no cenário da liberdade de expressão no contexto da disputa eleitoral. Nota-se que, muitas vezes, os tribunais e juízes eleitorais acabam invertendo o entendimento predominante em relação à liberdade de expressão em detrimento dos direitos da personalidade. Ou seja, ao invés de considerar válida toda e qualquer manifestação de pensamento no pleito eleitoral, acaba coibindo determinadas manifestações. ${ }^{20}$

Tome-se como exemplo o quanto decidido na Representação no $165.865^{21}$ pelo Tribunal Superior Eleitoral: a Suprema Corte Eleitoral entendeu que no horário eleitoral gratuito caberia a veiculação apenas de conteúdos propositivos, ficando eventuais críticas limitadas às propostas e programas de governo dos adversários. A justificativa para tanto seria o fato de o horário eleitoral gratuito ser custeado através de recursos públicos, na forma de renúncia de tributos.

Instrumento importante, neste aspecto, seria a aplicação do direito ao esquecimento, atuando como verdadeiro protetor de direitos fundamentais. Este, que não é mais novidade em nosso ordenamento jurídico desde que foi parte do Enunciado no 531 da VI Jornada de Direito Civil, ao ser reconhecido como direito da personalidade, integra a esfera de proteção da própria dignidade humana. ${ }^{22}$

20 PEREIRA, Rodolfo Viana. Ensaio sobre o ódio e a intolerância na propaganda eleitoral. In: KIM, Richard Pae; NORONHA, João Otávio de. Sistema político e direito eleitoral brasileiro: estudos em homenagem ao Ministro Dias Toffoli. São Paulo: Gen/Atlas, 2016.

21 “ELEIÇÕES 2014. REPRESENTAÇÃO. DIREITO DE RESPOSTA. OFENSA À HONRA. HORÁRIO ELEITORAL. GRATUITO. BLOCO TELEVISIVO. MEDIDA LIMINAR. DEFERIMENTO" (TSE. Representação no 165865.2014.6.00.0000 - Classe 42 - Brasília -DF. Rel. Min. Admar Gonzaga, acórdão de 16.10.2014).

22 BITTENCOURT, IIla Barbosa; VEIGA, Ricardo Macellaro. Direito ao esquecimento. Revista Direito Mackenzie, v. 8 , n. 2 , p. $45-58$. p. 55. 


\section{A justificativa do referido enunciado dispõe o seguinte:}

Os danos provocados pelas novas tecnologias de informação vêm se acumulando nos dias atuais. 0 direito ao esquecimento tem sua origem histórica no campo das condenações criminais. Surge como parcela importante do direito do ex-detento à ressocialização. Não atribui a ninguém o direito de apagar fatos ou reescrever a própria história, mas apenas assegura a possibilidade de discutir o uso que é dado aos fatos pretéritos, mais especificamente o modo e a finalidade com que são lembrados. ${ }^{23}$

Pode-se dizer que o direito ao esquecimento representa um balizador de excessos e abusos que possam ser cometidos contra os direitos da personalidade na sociedade de informação. ${ }^{24}$ Há de se lembrar que todos os direitos fundamentais devem se inter-relacionar para garantir a preservação da dignidade da pessoa humana, logo, não são absolutos.

Nas lições de Sarlet, a possibilidade de ser "esquecido" e não sofrer permanentemente e indeterminadamente as repercussões negativas por fatos do passado é essencial não só para uma vida saudável pessoal, mas também para uma integração social do indivíduo. ${ }^{25}$

Ainda, tem-se que o reconhecimento do direito ao esquecimento no ordenamento jurídico não significa obrigar alguém, do ponto de vista individual, a esquecer algo, mas sim de um processo de esquecimento social, através da supressão de determinadas informações ou dificuldade de acesso a estas.

O direito ao esquecimento pode ser considerado um direito fundamental de natureza implícita a resguardar a dignidade humana, guardando relação com diversos direitos de personalidade como privacidade, intimidade, honra, imagem, como também de autodeterminação informativa, ao nome e à identidade pessoal, já reconhecidos pelo Supremo Tribunal Federal.

23 CONSELHO DA JUSTIÇA FEDERAL. Centro de Estudos Judiciários. VI Jornada de Direito Civil. Disponível em: https://www.cjf.jus.br/cjf/corregedoria-da-justica-federal/centro-de-estudos-judiciarios-1/publicacoes-1/ jornadas-cej/vijornadadireitocivil2013-web.pdf. Acesso em: 27 mar. 2020.

24 RUZYK, Carlos Eduardo Pianovski (Org.). Direito civil constitucional: a ressignificação da função dos institutos fundamentais do direito civil contemporâneo e suas consequências. Florianópolis: Conceito, 2014. p. 90.

25 SARLET, Ingo Wolfgang. Proteção da personalidade no ambiente digital: uma análise à luz do caso do assim chamado direito ao esquecimento no Brasil. Espaço Jurídico Journal of Law, Joaçaba, v. 19, n. 2, p. 491-530, maio/ago. 2018. Disponível em: https://portalperiodicos.unoesc.edu.br/espacojuridico/ article/view/17557/pdf. Acesso em: 13 abr. 2020. p. 497. 
Quando os candidatos utilizam a imagem e dados de seus adversários para construir uma campanha negativa, estão maculando sua honra e ferindo a proteção de seu direito à imagem, invioláveis e inerentes à condição humana. Muitas das vezes, tal utilização não possui qualquer interesse público e atual, requisitos apontados como inerentes à disseminação lícita de informações sobre outrem.

Estar-se-ia diante da necessidade de assegurar determinada possibilidade de autogovernar a própria memória e de poder reagir de algum modo à "implacável memória coletiva da internet", além de impedir que as pessoas fiquem prisioneiras de "um passado destinado a não passar". Entre os critérios que são exigidos para equilibrar o direito à informação, tem-se a atualidade e o interesse público na veiculação, o que também deve servir de contraponto à utilização de informações em campanhas eleitorais na internet.

Sem dúvidas, a vida de quem pretende ocupar um cargo eletivo resguarda, em certa proporção, interesse público. As condutas passadas podem, de fato, representar indícios de desvio de caráter ou qualidades favoráveis e positivas aos cargos almejados. Não se pretende sugerir que a população não tenha o direito a acessar informações sobre seus futuros prováveis representantes.

O cerne da discussão ora proposta é que tais informações não sejam manipuladas pelos candidatos para uma campanha eleitoral negativa e ofensiva a direitos fundamentais, devendo sempre observar as balizas impostas pelo próprio ordenamento. Quando informações antigas são ressuscitadas fora de um contexto de interesse público, no intuito único de construir uma persona extremamente negativa a um candidato, tais efeitos repercutem não apenas no contexto do pleito eleitoral (podendo influenciá-lo fortemente), como também em diversas esferas da vida privada do candidato.

Considerando que o ambiente da rede mundial transforma tudo que era material em virtual, o mesmo não se pode dizer das consequências de seu uso indevido. $\mathrm{Na}$ atuação dos internautas em manipular os dados e informações, não existe qualquer filtro ou preocupação com a veracidade dos fatos. Não são jornalistas, com uma profissão regulamentada. São pessoas aleatórias, com intenções das mais diversas. Os danos da utilização indevida de dados, fatos, fotos e informações na internet causam sérios prejuízos no mundo material.

0 fato de as relações sociais estarem sendo desenvolvidas no ambiente virtual não deveria significar estarem alheias à responsabilidade inerente à comunicação, posto que capazes de causar sérios prejuízos à vida das pessoas, tolhendo sua dignidade e afetando seu bem-estar, seja enquanto indivíduo ou ator social. 
Neste sentido as palavras de Steiner, no livro Direito civil constitucional:

Em outras palavras, não há direito à informação quando este se mostrar incompatível com a proteção de outro direito igualmente fundamental, qual seja, a proteção da personalidade e seus atributos mais sensiveis. Se a informação é um direito de todos, e também um dever da imprensa, a privacidade é um limite necessário a ser protegido e respeitado. ${ }^{26}$

Bem por isso, as campanhas, que traduzem um dever e uma faculdade inerente ao poder representativo do pleito eleitoral, devem resguardar estreito respeito aos direitos fundamentais, permitindo que as eleições se desenvolvam de forma moral, proba, com a disseminação de informações que guardem seus aspectos jurídicos e de atual interesse público.

Já em aplicabilidade do ordenamento jurídico brasileiro, muito embora carente de normatização específica (mesmo no contexto do Marco Civil da Internet), o direito ao esquecimento pode ser um importante instrumento a ser manejado pelos tribunais pátrios quando da análise de requerimentos para retirada de informações pessoais constantes em campanhas eleitorais construídas de forma negativa.

Através da análise de cada caso concreto é que os juízes podem exercer a conhecida técnica de ponderação de princípios fundamentais, construída a partir da teoria do alemão Robert Alexy. A partir desta é que se estabelece qual princípio fundamental deve prevalecer, ou seja, qual acaba pesando mais (daí o nome da técnica: sopesamento) naquele caso.

Aqueles fatos uma vez noticiados que dizem respeito à vida privada de alguém, já acobertados pelo esquecimento diante do transcurso do tempo e que injustificadamente são trazidos à tona provocando prejuízos e ofensas dão, como destacado, o direito ao ofendido de buscar judicialmente a exclusão destas informações da mídia. ${ }^{27}$

26 Apud RUZYK, Carlos Eduardo Pianovski (Org.). Direito civil constitucional: a ressignificação da função dos institutos fundamentais do direito civil contemporâneo e suas consequências. Florianópolis: Conceito, 2014. p. 97.

27 VENDRUSCOLO, Mariana Tagliari; SILVA, Cláudio Eduardo Regis de Figueiredo e. Políticos candidatos e o direito ao esquecimento - (Im)possibilidade de aplicação na propaganda eleitoral obrigatória no rádio e televisão. Revista da ESMESC, v. 21, n. 27, 2014. Disponível em: https://revista.esmesc.org.br/re/ article/download/96/83. Acesso em: 13 abr. 2020. p. 71. 
Assim, fazendo o uso da técnica de sopesamento ou ponderação, o magistrado é capaz de conferir a correta proteção, tanto ao direito à informação ou liberdade de expressão quanto aos direitos da personalidade, garantindo que 0 processo eleitoral seja conduzido de forma hígida.

Refletir sobre a utilização da internet no contexto das campanhas eleitorais, então, é resguardar não apenas a higidez do próprio pleito eleitoral quanto os direitos fundamentais dos candidatos envolvidos, sejam eles relacionados à eleição ou à sua vida privada.

\section{Considerações finais}

Diante das referidas considerações, pode-se constatar que a campanha eleitoral na internet deve, também, observar os direitos fundamentais inerentes à proteção da pessoa humana.

$\mathrm{O}$ fato de a internet disponibilizar uma infinidade de dados e informações pessoais não significa que eles possam ser usados de qualquer forma, manipulados e descontextualizados, muitas vezes, no fito de criar imagens negativas sobre os envolvidos no pleito eleitoral.

A liberdade inerente ao ambiente virtual, que em muito auxilia a propagação de campanhas e propostas eleitorais, fortalecendo o direito do eleitor em conhecer seus candidatos, não pode significar uma atuação à margem dos direitos da personalidade.

Direitos como a imagem, a honra e a privacidade são constantemente prejudicados nas propagandas eleitorais, muitas vezes sob o manto do exercício do direito à informação ou liberdade de expressão.

De fato, tais direitos devem ser privilegiados num Estado Democrático, mas podem (e devem) ser feitos sem prejudicar outros direitos fundamentais. Neste sentido a importância do direito ao esquecimento, que pode ser um indispensável instrumento na proteção dos direitos da personalidade.

0 direito ao esquecimento é capaz de ponderar o interesse público na divulgação de determinadas informações sobre os candidatos, permitindo que a corrida eleitoral seja, de fato, respeitosa e preserve os princípios mais basilares do direito.

Se deve o direito evoluir à medida em que os fatos sociais vão se desenvolvendo, não pode ele estar alheio ao contexto da campanha eleitoral na internet, devendo atuar tanto na normatização que efetivamente garanta direitos fundamentais na rede, quanto na construção de um entendimento jurisprudencial sólido neste sentido. 
Através do reconhecimento do direito ao esquecimento, os tribunais pátrios podem analisar a pertinência no uso de dados pessoais disponibilizados na internet, e a forma como estão sendo manipulados por determinados candidatos. 0 enfrentamento desta questão, principalmente quando considerada na perspectiva de preservar o sistema democrático, é tanto urgente quanto indispensável à nova ordem mundial ocasionada pela internet.

Logo, a pretensa reflexão que se pretende a partir desta análise centra-se na ideia de que o ambiente virtual assim como as demais formas de representação e expressão social não podem ser conduzidos à margem do direito. 0 direito ao esquecimento acaba sendo um protetor e balizador de direitos fundamentais à medida que limita que fatos resguardados na memória antiga sejam reavivados para prejudicar o cenário atual da imagem ou honra de outrem.

\title{
The right to be forgotten face the conflict of fundamental rights at electoral campaign in the internet
}

\begin{abstract}
Nowadays, it is repetitive to bring the reflection about how the digital world possesses us. We are immersed, in every way, in this network of data, contacts, information and interactions. In this perspective, the present study seeks to make a critical analysis on how some fundamental rights conflict in the virtual environment, from the perspective of the electoral campaign. It is mainly considered as the right to honor, privacy and image are constantly opposed to freedom of expression and information, especially with the facilities allowed by the virtual environment. The hypothesis raised is that, like any fundamental right, freedom of expression is not absolute, and should respect the rights that protect the personality, bringing the right to be forgotten as a standard in the balance between such rights. The method to be used for this research will be, first of all, the deductive method, searching, from the general idea of this problem (conflict of fundamental rights), to explore its specificities, investigating especially the possible alternatives.
\end{abstract}

Keywords: Right to forgotten. Democracy. Personality rights. Freedom of expression. Election campaign.

Contents: Introduction - $\mathbf{1}$ Election campaigns in the digital age: new outlines of representative democracy $-\mathbf{2}$ Conflict between personality rights and freedom of expression in the internet election campaign - $\mathbf{3}$ The right to be forgotten as an instrument for the preservation of fundamental rights Final considerations - References

\section{Referências}

ALEXY, Robert. Teoria dos direitos fundamentais. 2. ed. Tradução de Virgílio Afonso da Silva. São Paulo: Malheiros, 2011.

ALMEIDA, Roberto Moreira de. Curso de direito eleitoral. 12. ed. Salvador: JusPodivm, 2018.

ARAÚJO, Luiz Alberto David; NUNES JÚNIOR, Vidal Serrano. Curso de direito constitucional. São Paulo: Saraiva, 2009.

BITTENCOURT, Illa Barbosa; VEIGA, Ricardo Macellaro. Direito ao esquecimento. Revista Direito Mackenzie, v. 8, n. 2, p. 45-58. 
BRANCO, Paulo Gustavo Gonet. Aspectos da teoria geral dos direitos fundamentais. In: BRANCO, Paulo Gustavo Gonet; MENDES, Gilmar Ferreira; COELHO, Inocêncio Mártires. Hermenêutica constitucional e os direitos fundamentais. Brasília: Brasília Jurídica, 2000.

CASTELLS, Manuel. A galáxia da internet: reflexões sobre internet, negócios e sociedade. Lisboa: Fundação Calouste Gulbenkian, 2004.

CONSELHO DA JUSTIÇA FEDERAL. Centro de Estudos Judiciários. VI Jornada de Direito Civil. Disponível em: https://www.cjf.jus.br/cjf/corregedoria-da-justica-federal/centro-de-estudos-judiciarios-1/publicacoes-1/ jornadas-cej/vijornadadireitocivil2013-web.pdf. Acesso em: 27 mar. 2020.

GOMES, Wilson. Participação política online: questões e hipóteses de trabalho. In: GOMES, W.; MAIA, R.; MARQUES, F. J. (Orgs.). Internet e participação política no Brasil. Porto Alegre: Sulina, 2011.

LÉVY, Pierre. As tecnologias da inteligência. Rio de Janeiro: Editora 34, 1993.

LIMA, Erik Noleta Kirk Palma. Direito ao esquecimento: discussão europeia e sua repercussão no Brasil. Revista de Informação Legislativa, ano 50, n. 199, jul./set. 2013.

MANHANELLI, Carlos Augusto. Eleição é guerra. São Paulo: Summus, 1992.

MARQUES, Francisco Paulo Jamil. Ciberpolítica: conceitos e experiências. Salvador: EDUFBA, 2016.

MONNERAT, Alessandra; RIGA, Matheus; RAMOS, Pedro. Fake news devem causar impacto em eleições de 2018. Estadão. Disponível em: http://infograficos.estadao.com.br/focas/politico-em-construcao/ materia/fake-news-devem-causar-impacto-em-eleicoes-de-2018. Acesso em: 11 dez. 2018.

MORAES, Alexandre de. Direito constitucional. 32. ed. São Paulo: Atlas, 2016.

PEREIRA, Rodolfo Viana. Ensaio sobre o ódio e a intolerância na propaganda eleitoral. In: KIM, Richard Pae; NORONHA, João Otávio de. Sistema político e direito eleitoral brasileiro: estudos em homenagem ao Ministro Dias Toffoli. São Paulo: Gen/Atlas, 2016.

REGO, Francisco Gaudêncio Torquato do. Marketing político e governamental: um roteiro para campanhas políticas e estratégias de comunicação. São Paulo: Summus, 1985.

RUZYK, Carlos Eduardo Pianovski (Org.). Direito civil constitucional: a ressignificação da função dos institutos fundamentais do direito civil contemporâneo e suas consequências. Florianópolis: Conceito, 2014.

SARLET, Ingo Wolfgang. Proteção da personalidade no ambiente digital: uma análise à luz do caso do assim chamado direito ao esquecimento no Brasil. Espaço Jurídico Journal of Law, Joaçaba, v. 19, n. 2, p. 491-530, maio/ago. 2018. Disponivel em: https://portalperiodicos.unoesc.edu.br/espacojuridico/ article/view/17557/pdf. Acesso em: 13 abr. 2020.

VENDRUSCOLO, Mariana Tagliari; SILVA, Cláudio Eduardo Regis de Figueiredo e. Políticos candidatos e o direito ao esquecimento - (Im)possibilidade de aplicação na propaganda eleitoral obrigatória no rádio e televisão. Revista da ESMESC, v. 21, n. 27, 2014. Disponível em: https://revista.esmesc.org.br/re/ article/download/96/83. Acesso em: 13 abr. 2020. 
Informação bibliográfica deste texto, conforme a NBR 6023:2018 da Associação Brasileira de Normas Técnicas (ABNT):

DAMÁZIO, Marcela Queiroz de França; ANDRADE, Diogo de Calasans Melo. O direito ao esquecimento ante o conflito de direitos fundamentais nas propagandas eleitorais na internet. Direitos Fundamentais \& Justiça, Belo Horizonte, ano 14, n. 42 , p. 251-268, jan./jun. 2020.

Recebido em: 07.03.2019

Pareceres: 17.04.2019, 07.10.2019, 26.03.2020

Aprovado em: 26.03.2020 